\title{
HISTORY
}

Copyright $(\odot 2018$ by the Kalmyk Scientific Center of the Russian Academy of Sciences

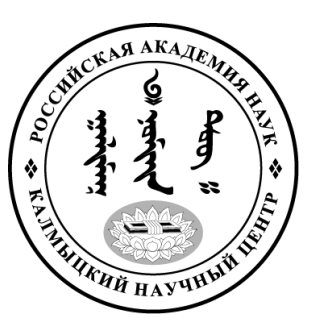

Published in the Russian Federation

Oriental Studies (Previous Name: Bulletin of the Kalmyk Institute for Humanities of the Russian Academy of Sciences)

Has been issued as a journal since 2008

ISSN: 2619-0990; E-ISSN: 2619-1008

Vol. 38, Is. 4, pp. 2-10, 2018

DOI 10.22162/2619-0990-2018-38-4-2-10

Journal homepage: https://kigiran.elpub.ru

УДК 294.311+94(540)

\section{Буддизм и политизация религии в Индии: Наваяна Бхимрао Амбедкара}

Дарима Дашиевна Амоголонова ${ }^{1}$

${ }^{1}$ доктор исторических наук, ведущий научный сотрудник, Институт монголоведения, буддологии и тибетологии CO PAH (670031 Россия, г. Улан-Удэ, ул. Сахьяновой, 6). ORCID: 00000002-1176-4095. E-mail: amog@inbox.ru

Аннотация. В статье исследуется политическая, социальная и религиозная деятельность Бхимрао Рамджи Амбедкара, основателя Наваяны - современного буддизма в Индии. Выдающийся политик и юрист, Амбедкар с юности посвятил свою жизнь борьбе за права неприкасаемых, к которым и сам принадлежал. Амбедкар был убежден, что главные проблемы Индии заключаются в индусских традициях, а именно в варно-кастовой системе, препятствующей формированию единой нации и гражданского общества на основаниях равенства и свободы личности. Преодоление традиционной социальной организации и победу над индуизмом он видел в возвращении в Индию буддизма, который способен объединить народ и противостоять индусской жесткой социальной иерархии и стратификации.

В период борьбы за независимость, когда индийский национализм строился на идеях М. К Ганди, тесно связанных с политизированным индуизмом, Амбедкар не выдвинул общенациональной программы действий, оставаясь лидером неприкасаемых, которые составляли значительную социальную группу и были одним из объектов агитации М. К. Ганди и Индийского Национального Конгресса. Вследствие этого Амбедкар оказался в оппозиции к индусским лидерам, тем не менее снискав авторитет среди разных слоев индийского общества.

После достижения независимости Амбедкар включился в активную работу по созданию законодательной базы страны, стал «отцом индийской Конституции». Одновременно он стремился реформировать индусское традиционное право с целью его модернизации и демократизации для улучшения положения женщин и социальных низов в лице неприкасаемых. Однако когда попытки потерпели неудачу, Амбедкар еще активнее занялся антииндусской агитацией среди внекастовых сограждан.

Главным событием жизни Амбедкара стало его личное и его сторонников обращение в буддизм в 1956 г. Модернизированный буддизм - Наваяна - основывается на принципах, которые были сформулированы Амбедкаром, но при этом опирается на первоначальное Учение Будды, сохраненное в палийском каноне. Число буддистов-амбедкарианцев растет вследствие отказа неприкасаемых от индуизма в условиях нежелания властей коренным образом изменить положение бесправных слоев населения. Политическое оформление Наваяны выражается в деятельности партий и организаций, хотя их вес в индийской политике пока невелик. Однако идеи эгалитаризма и демократии, сформулированные Амбедкаром, находят в Индии все более широкое распространение.

Ключевые слова: Бхимрао Амбедкар, Наваяна, буддизм, индуизм, неприкасаемые, варны, касты 
В первой половине XX в. борьба за независимость вовлекла в связанные с нею политические процессы огромные массы индийского населения. Две главные религии - индуизм и ислам - играли роль символов национального духа и единения против Великобритании, а в течение непродолжительного времени, в период халифатского движения, индусские и мусульманские лидеры даже выступали единым фронтом, однако позже их пути разошлись, а в Индии укрепилась идея существования «двух наций», что впоследствии привело к разделу страны.

На первый взгляд, буддизм в общем освободительном подъеме не особо выделялся. Однако его роль в социальных процессах внутри индийского общества была значительной, поскольку в политической мобилизации разных социальных слоев буддизм становится защитником неприкасаемых, представляющих самые бесправные, униженные и бедные группы населения. Возвращение буддизма в страну его возникновения обусловлено сложнейшими проблемами внутри индусского сообщества, остававшегося традиционным и подчинявшегося правилам, сформировавшимся в древности.

Бхимрао Рамджи Амбедкар (1891-1956), родившийся в семье неприкасаемых и, несмотря на это, сумевший подняться на социальном лифте до статуса общенационального лидера и Отца индийской конституции, полагал, что главной причиной отсталости Индии и ее многочисленных бед являются индуизм и его варно-кастовые устои, а вовсе не британское владычество. Он не верил обещаниям лидеров освободительного движения, особенно Мохандасу Карамчанду (Махатме) Ганди, о том, что кастовая несправедливость будет преодолена путем полного уничтожения явления неприкасаемости: «Невозможно поверить, что хинду когда-либо смогут принять неприкасаемых в свое сообщество ${ }^{1}$. Их кастовая система и

\footnotetext{
${ }^{1}$ Вопрос о том, являются ли неприкасаемые членами индусского религиозного сообщества, не предполагает однозначного ответа. С одной стороны, они носят индусские имена и соблюдают определенные правила индуизма. Кроме того, многие из них идентифицируют себя в качестве хинду. С другой стороны, они не имеют доступа к индусскому традиционному образованию, не имеют права читать священные книги категории шрути, не могут посещать храмы, многие важные индусские обряды им недоступны.
}

религия полностью отрицают любую надежду на продвижение в этом направлении. Но есть неисправимые оптимисты, и их больше среди кастовых хинду, чем среди неприкасаемых, которые считают, что ассимиляция возможна. $<\ldots>$ Нет сомнения, что этот процесс будет длиться веками, а тем временем неприкасаемые будут продолжать жить под социальной и политической властью хинду и страдать от тирании и притеснений, которым они подвергаются с древности» [Ambedkar vol. 12, 2014: 731]2.

Что касается британской власти, то Амбедкар ощутил на собственной судьбе, что она принесла с собой модернизацию и европеизацию, благодаря которым перед ним открылись пути к самореализации: он получил в Индии школьное и университетское образование, окончил университет в США, защитил диссертацию в Великобритании, успешно занимался профессиональной деятельностью в качестве юриста, экономиста и политика.

Амбедкар был первым неприкасаемым, поступившим в высшее учебное заведение в Индии - Бомбейский университет. При этом Амбедкар вполне осознавал, что британские власти не имеют намерения вмешиваться в дела, касающиеся индусской варно-кастовой стратификации, а потому то, чего он сам добился в жизни, недоступно для подавляющего большинства низкокастовых и неприкасаемых членов индусского сообщества. Препятствием служит варно-кастовая иерархия, согласно которой «род занятий назначается людям заранее, не на основании их способности к обучению, а только из-за социального статуса их родителей» [Naik 2003: 156].

Если абстрагироваться от нравственной стороны проблемы неприкасаемости и взглянуть на нее с точки зрения социальной экономики, то можно заключить, что предопределенность лишает человека выбора и не дает реализовать себя в достойном труде; человек не стремится к лучшей жизни, а потому «скорее будет голодать, чем займется другой работой, и причина этого заключается в кастовой системе. Каста стала прямой причиной массовой безработицы в Индии» [Naik 2003: 156].

Для Амбедкара было важно, чтобы неприкасаемые осознали, что избавление от унизительного статуса является их главной

2 Здесь и далее перевод с английского выполнен мной. - Д. $A$. 
социальной и политической задачей. С этой целью он издает газеты (хотя подавляющее большинство неприкасаемых было неграмотно), выступает на митингах, а в 1924 г. создает организацию Бахишкрут Хитакарни Сабха (Ассоциация благосостояния низших (депрессивных) классов) под лозунгом «Обучение, агитация и организация», что стало началом его борьбы за права неприкасаемых.

Большой резонанс в обществе вызвали его акции, такие как нарушение запрета неприкасаемым пользоваться водой из водоемов для кастовых хинду. В целом уже с конца 1920-х и особенно в 1930-е гг. Амбедкар становится лидером неприкасаемых, среди которых распространяет свои взгляды на религию: «Индуизм - это религия, которая не основывается на нравственности» [Ambedkar 1980: 5]. При этом он определенно заявлял, что сам не намерен оставаться хинду: «Я родился с позором неприкасаемости, поскольку не мог этого контролировать. Тем не менее, я не умру хинду» [Ambedkar vol. 18, p. 1, 2014: 430].

Призывая неприкасаемых принять такое же решение, на конференции махаров ${ }^{1}$ в Бомбее в 1936 г. Амбедкар сформулировал причины, по которым низкорожденным следует сделать решительный выбор и навсегда отказаться от унизительного статуса: «Религия для человека, а не человек для религии. $<\ldots>$ Если вы хотите создать общество, которое обеспечивает сотрудничество и братство - измените вашу религию. $<\ldots>>$ Если вы хотите сделать счастливым мир, в котором живете - измените вашу религию. Разве вы хотите остаться привязанными к религии, которая даже не считает вас людьми? Почему вы остаетесь в религии, которая запрещает вам входить в ее храмы? Почему вы остаетесь под властью религии, которая запрещает вам набирать воду из общественных колодцев? < ..> Почему вы остаетесь в религии, которая оскорбляет вас на каждом шагу? Религия, которая учит человека относиться к другому человеку не так, как положено между людьми, это не религия, а насмешка» (цит. по: [Wankhede 2009: 172]).

Своими выступлениями и призывами на собраниях, митингах и в газетах Амбедкар снискал большую популярность в разных слоях общества (хотя далеко не все разделяли его взгляды), добился признания себя

${ }^{1}$ Махары - маратхская каста неприкасаемых, из которой происходил сам Амбедкар. в качестве лидера, с которым приходилось считаться и британской администрации, и индийским политическим деятелям, таким как М. К. Ганди. Одновременно с деятельностью в качестве лидера низкорожденных, Амбедкар принимал участие в политических событиях и преобразованиях. В 1936 г. он создал Независимую лейбористскую партию, в 1942 г. стал министром труда в совете при вице-короле, распустил лейбористскую партию и создал на ее основе Федерацию зарегистрированных каст и племен, подразумевавших далитов и адиваси ${ }^{2}$.

В правительстве независимой Индии Амбедкар стал министром юстиции, членом учредительного собрания по подготовке Конституции и автором законопроекта по кодификации индусского права.

Амбедкар подошел к созданию конституции Индии и к подготовке законопроекта как к главным задачам своей жизни, хотя осознавал, насколько трудно ему будет доказывать свою правоту, особенно в отношении изменений в индусском праве. Что касается Конституции, то работа Амбедкара в качестве председателя комитета по ее подготовке была оценена как настоящий триумф. Хотя авторов Конституции было много, все же именно Амбедкар по праву считается отцом этого документа, самого большого в мире. Согласно Конституции, Индия является суверенной, социалистической, светской и демократической республикой, в которой запрещена дискриминация по мотивам религиозной, расовой, кастовой принадлежности, пола или места рождения.

В своей работе по кодификации индусского права Амбедкар столкнулся с сопротивлением со стороны и политиков, и индусского населения, поскольку четыре акта

2 Далит (угнетенный, подавленный) - термин, введенный в XIX в. для обозначения неприкасаемых Махатмой Джьотирао Пхуле, маратхским просветителем и гуманистом, шудрой по происхождению. Этот термин стал наиболее употребительным, в том числе и в современной Индии. Адиваси (старые или первые жители) - различные этнические группы, считающиеся первоначальными жителями индийского субконтинента, официально именуемые зарегистрированными племенами и составляющие около $8 \%$ населения Индии. Они не включены в кастовую систему, для их социальной организации характерна клановость, а культура (мифы, религиозные воззрения и обряды) заметно отличается от индусской. 
законопроекта изменяли статус женщин, далитов, прав наследования и прав усыновленных, что коренным образом нарушало традиционное индусское право. Иными словами, Амбедкар, руководствуясь государственными и социальными интересами, вторгся в область, регулируемую традициями, в частности Законами Ману. И хотя сам он утверждал, что в основе его нововведений лежат шастры и стремление упрочить единство страны и социальный прогресс, его законотворчество столкнулось с сопротивлением. В результате в 1951 г. законопроект провалился в парламенте, а Амбедкар подал в отставку. Соответствующие законы были приняты в 1955 г. с существенными правками.

Одновременно Амбедкар продолжал поиски лучшей религии, что заняло около двадцати лет. К концу 1940-х гг. Амбедкар сформулировал идею, что для Индии в целом и для далитов в частности лучшей религией является буддизм, который, в отличие от христианства и ислама, является национальной религией, т. е. исторически коренящейся в индийской культуре: «Я выберу только наименее губительный путь для страны. И это самая большая польза, которую я дарую стране, принимая буддизм, поскольку буддизм - это часть и послание индийской культуры. Я позаботился, чтобы мое новообращение не повредило традиции культуры и истории нашей страны» (цит. по: [Keer 1971: 498]).

В целом его идея обращения в буддизм строилась на самой критической оценке индуизма: «Религия, которая предписывает различия между своими адептами, является неполной, а религия, которая к миллионам приверженцев относится хуже, чем к собакам и преступникам, и причиняет им невыносимые страдания, и вовсе не является религией. Такой несправедливый порядок не может называться религией. Религия несовместима с рабством. Будда выступал за социальную свободу, интеллектуальную свободу, экономическую свободу и политическую свободу. Он учил равенству, равенству не только мужчин, но и равенству мужчин и женщин. Равенство - это основополагающий принцип буддизма. Был только один человек, который поднял свой голос против сепаратизма и неприкасаемости, и это был Господь Будда» [Dr. Ambedkar + Sangharakshita].
В беседе под названием «Почему я люблю буддизм, и как он полезен миру в современных условиях» с журналистами ВВС накануне обращения в буддизм Амбедкар сказал: «Я предпочитаю буддизм, потому что он дает три принципа в сочетании, чего нет в других религиях. Буддизм учит Праджне (понимаемой как отсутствие предрассудков и супернатурализма), Каруне (любовь между людьми в противоположность отношениям раба и хозяина) и Самати (равенство) (цит. по: [Teltumbde 2017: 116]).

14 октября 1956 г. в Нагпуре, Махараштра, в местности, ныне именуемой Дикшабхуми (земля, где произошло обращение), Бхимрао Амбедкар и его жена в присутствии большого числа людей приняли учение о трех прибежищах и пяти заповедях от бирманского бхиккху Чандрамани, проведшего большую часть жизни в Кушинагаре, где Будда обрел паринирвану ${ }^{1}$ Затем Амбедкар огласил 22 клятвы, автором которых был он сам и в которых полностью отверг все индусские религиозные практики и поклялся следовать учению Будды.

Примечательно, что в клятвах Амбедкара значительное место занимают те, где говорится об отречении от индуизма, его богов и обрядов ${ }^{2}$, что подтверждает протестный характер обращения в буддизм и модернистское содержание амбедкарианского

1 Чандрамани (1876-1972) - бирманский монах, приехавший в Индию с миссионерскими целями. Вместе с индийским монахом Махавирой Свами, обучавшимся в Шри-Ланке, в 1902 г. основал в Кушинагаре вихару и на бирманские средства начал восстанавливать две разрушенные ступы и храм с 30-метровой статуей Будды, уходящего в паринирвану.

${ }^{2}$ Семь антииндусских клятв Амбедкара: 1. Я не буду верить в Брахму, Вишну или Махешу (одно из имен Шивы. - Д. А. ), и я не буду им поклоняться; 2. Я не буду верить в Раму или Кришну, которые считаются воплощениями Бога, и не буду им поклоняться; 3. Я не буду верить в Гаури (Парвати. - Д. А.), Ганапати (Ганеша. - Д. $A$.) или в любого иного бога хинду и не буду им поклоняться; 4. Я не верю, что у Бога есть аватары; 5. Я не верю и не буду верить, что Господь Будда - это аватара Вишну. Я считаю такое суждение чистым безумием и ложной пропагандой; 6. Я не буду совершать обряды шраддха (для предков) или пиндадана (для ушедших); $<\ldots>8$. Я не позволю, чтобы брахманы совершали для меня обряды (цит. по: [Sadangi 2008: 315-316]). 
ревайвализма, состоящее, во-первых, в цели добиться социального реформирования и, во-вторых, в попытках представить обновленную религию как научную или хотя бы совместимую с современной наукой.

Кроме того, Амбедкар намеренно выступил в качестве светского проповедника, доказывая, что хотя предлагаемая им Наваяна опирается на традиции Тхеравады, она будет не монастырской и не монашеской. Поэтому вопреки традиции Амбедкар лично обратился со словами о трех прибежищах и пяти заповедях ко всем собравшимся, общее число которых было, как считается, около 600 тысяч. 380 тысяч ответили утвердительно на его призыв стать буддистами. После этого они выслушали 22 клятвы и поклялись следовать им.

На следующий день там же, в Дикшабхуми, собралось 100 тысяч человек, которые обратились в буддизм под руководством Амбедкара.

Так была создана Сангха последователей Наваяны - Четвертой Колесницы, после Тхеравады, Махаяны и Ваджраяны. В настоящее время Наваяна именуется также Бхимаяной в честь Амбедкара.

Между 7 декабря 1956 г. и 10 февраля 1957 г., т. е. в течение двух месяцев, церемонии обращения состоялись в Бомбее, Дели, Агре и в более чем двадцати прочих городах, главным образом, в Махараштре. Число буддистов-амбедкарианцев выросло от 750 тысяч, обращенных самим Амбедкаром в Нагпуре и Чанде, до 4 млн чел. [Sangharakshita 2006: 163].

Наваяна имеет ряд догматических особенностей, разработанных Амбедкаром и содержащихся в главной книге его жизни «Будда и его Дхамма». В книге Амбедкар высказывает свои суждения о том, каким изначально был буддизм и как он менялся под воздействием брахманистского климата. В качестве примера он приводит понятие карма (камма). В отличие от брахманизма, а позже индуизма, в буддизме карма не связана с личными заслугами или проступками личности: «Закон каммы имеет отношение только к вопросу об общем нравственном порядке. Он не имеет ничего общего с удачами или несчастьями отдельного человека. Он связан с поддержанием нравственного порядка во всей вселенной» [Ambedkar 1974: 172-173].

Можно сделать вывод, что Амбедкар рассматривал буддийский закон кармы ина- че, чем это принято, т. е. он отказывается от трактовки, отождествляющей ее понимание в буддизме и брахманизме: «доктрина кармы, проистекающей из предыдущего рождения - это чисто брахманистская доктрина. Карма предыдущего рождения, влияющая на нынешнюю жизнь, полностью совпадает с брахманистской доктриной о душе, воздействии кармы на душу. Но она совершенно несовместима с буддийским учением об отсутствии души. Она была полностью привнесена в буддизм кем-то, кто хотел сделать буддизм схожим с индуизмом, или кто не знал буддийского учения. <..> Основы учения индуизма о прошлой карме как регуляторе будущей жизни являются несправедливыми. <..> Единственной целью этого учения является предоставление возможности государству или обществу снять с себя ответственность за положение бедных и слабых. Иначе подобное бесчеловечное и абсурдное учение никогда не было бы придумано. Невозможно представить себе, что Будда, известный как Маха Каруника ${ }^{1}$, мог поддержать подобное учение» [Ambedkar 1974: 247-248].

Другой темой обсуждения Амбедкар избирает один из краеугольных камней буддизма - Четыре Благородные Истины: «Эта формула в корне противоречит буддизму. Если жизнь - страдание, смерть страдание и перерождение - страдание, тогда всему наступает конец. Ни религия, ни философия не могут помочь человеку достичь счастья в мире. <..> Четыре Арийские Истины - это самый большой камень преткновения на пути не-буддистов, желающих принять буддийскую проповедь, потому что Четыре Арийские Истины отказывают человеку в надежде, они превращают проповедь Будды в проповедь пессимизма. Составляют ли они часть оригинального учения или были позже добавлены монахами?». Отвечая на этот вопрос, Амбедкар утверждает, что Будда говорил о том, что жизнь - это страдание, с той лишь целью, чтобы показать, что на самом деле жизнь человека очень ценна ${ }^{2}$. Об этом свидетельствует, по мнению Амбедкара, возможность и необходимость избавления от страданий,

\footnotetext{
${ }^{1}$ Маха Каруника (maha kārunika) - Великий Сострадающий.

2 Уместно отметить, что и в брахманизме рождение в облике человека считается великой удачей, ибо только человек может выйти из круга перерождений и достичь Брахмана.
} 
а учитель, который указывает путь к избавлению, не может быть обвинен в пессимизме [Ambedkar 2014, vol. 11: 512].

Модернизация религии по Амбедкару неминуемо подразумевала вопрос о том, какой именно буддизм он избрал в качестве основы своего и своих последователей обращения. В интервью накануне 14 октября 1956 г. Амбедкар заявил, что он не желает вовлекать своих сторонников в споры по поводу различий между Хинаяной и Махаяной и что в Наваяне речь идет только об учении самого Будды. В этой связи в книге «Будда и его Дхамма» уделяется внимание вопросу о монашестве: «С какой целью Будда создавал бхиккху ${ }^{1}$. Было ли его целью создание совершенного человека? <..> Если бхиккху всего лишь совершенный человек, он бесполезен в распространении буддизма, потому что в качестве совершенного человека он эгоистичен. Но если он социальный слуга, тогда он может стать надеждой буддизма. Этот вопрос должен решаться не столько в интересах доктринальной логики, сколько в интересах будущности буддизма» [Ambedkar vol. 11, 2014: 14-15]. Сангха, в которую входят именно такие бхиккху (совсем необязательно монахи), состоит из людей, для которых важнее всего самосовершенствование, означающее праведность, просвещенность и сострадание [Ambedkar 1974: 24-35]. Амбедкар придавал вопросу о современной сангхе большое значение, поскольку для него она подразумевала модель общества и отношений в нем на основе моральных и социальных принципов Учения Будды. Основой деятельности сангхи становится социальное служение, а движущей силой - интеллектуальная элита, нацеленная на усовершенствование мира. В этом смысле Амбедкар вполне солидарен с М. К. Ганди, который тоже мечтал о гармоничном сообществе Индии, строящемся, однако, на идее взаимного служения варн. Новая буддийская община по Амбедкару не будет монашеской, что и означает его принципиально новый поворот - от традиции к современности. При этом Амбедкар проводит сравнение между религиозностью до Будды и в буддийский период: «Время, предшествующее жизни Будды, было одним из самых темных веков в истории Индии. Интеллектуально это была отсталая эпоха. Мышление подчинялось безоговорочному

${ }^{1}$ Бхикшу или бхиккху - монах, живущий на подаяния. почитанию священных книг. <..> Настоящие этические идеи, такие как самопожертвование или чистота желаний, не находили достойного места в нравственном сознании того времени. <..> В Ведах мы находим молитву, восхваления и поклонение. В буддизме впервые мы видим воспитание разума, чтобы побудить его действовать справедливо» [Ambedkar vol. 11, 2014: 595].

Наряду с обсуждением догматических основ буддизма, Амбедкар обращается к буддийской религиозной мифологии и приходит к выводу о явном внешнем влиянии (без сомнения, речь идет об эпическом брахманизме), поскольку ему представлялось неубедительным популярное жизнеописание Будды: «Зачем Будда принял паривраджью? Традиционный ответ на этот вопрос объясняет, что он принял паривраджью, потому что увидел похоронную процессию, больного человека и старика. Такой ответ абсурден. Будде было 29 лет, когда он принял паривраджью. Как случилось, что он не видел всех этих печальных зрелищ ранее? Ведь все это рядовые явления, с которыми сталкиваешься очень часто, и Будда не мог не видеть их раньше» [Ambedkar vol. 11, 2014: 13-14].

Амбедкар предлагает политическое объяснение паривраджьи как более достоверное и соответствующее историческим реалиям: Гаутама решается на уход из дома, чтобы шакьи, вассалы Кошалы, избежали кровопролитной войны с племенем колия, с которым раджа Кошалы был в состоянии военного конфликта из-за воды для полива полей ${ }^{2}$ [Ambedkar vol. 11, 2014: 24, 26-29]. Даже когда конфликт был исчерпан, Гаутама не вернулся, поскольку посвятил себя прекращению войн и ненависти в целом. Таким образом, Гаутама покинул дом для решения проблемы социального конфликта, который и является страданием-дуккха [Ambedkar 2014, vol. 11: 57-58].

${ }^{2}$ В соответствии с научными данными, которые признаются и сейчас, Амбедкар представлял политическую организацию племени шакья как либо республику, либо олигархию. При этом главенствующие семьи управляли территорией по очереди, причем глава правящей семьи носил титул раджи - вождя, а (военный) совет именовался гана или сангха [Ambedkar vol. 11, 2014: 1]. К моменту рождения Будды шакья признали свою зависимость от раджи Кошалы, без одобрения которого были невозможны выборы нового вождя шакьев. 
Бхимрао Рамджи Амбедкар, Бабасахиб, был буддистом всего семь недель. Но Наваяна продолжает оставаться реальной социальной силой, а жизнь и деятельность Амбедкара стали образцом для тех далитов, которые стремятся к повышению своего статуса, хотя истинного успеха достигают немногие. Самые яркие примеры - это Кочерил Раман Нараянан (президент Индии в 1997-2002 гг.) и нынешний президент Рам Натх Ковинд, оба далиты.

Социальная философия, политическая карьера и деятельность Амбедкара, безусловного лидера индийской демократии, вдохновляет многих низкорожденных.

Каждый год 14 октября в буддизм обращаются десятки и даже сотни тысяч человек. Среди них не только далиты, но и представители варн. Кроме того, наступление на права низших слоев индусского общества сопровождается обращением в буддизм и в другие, не сакральные, даты. Так, в апреле 2018 г. в связи с безответственной инициативой правительства Моди по изменению закона о преступлениях против представителей зарегистрированных каст за один лишь день буддистами стали 500 человек только в одном городке Ширазгаон (Махараштра) и 300 человек - в городке Уна (Гуджарат).

В современной индийской политике воззрения Амбедкара нашли идейное продолжение в деятельности партии Бахуджан Самадж (БСП, «партия сообщества большинства»), созданной в 1984 г. и декларирующей свои принципы как основывающиеся на учении Будды и Амбедкара.

Основатель партии, Канши Рам (1934 2006), утверждал, что социальной базой его партии являются низкокастовые группы населения Индии, а также зарегистрированные касты, племена и религиозные меньшинства, такие как сикхи, мусульмане, христиане, парсы, буддисты. Все вместе эти группы населения составляют, по мысли Канши Рама, абсолютное большинство населения - не менее 80 \%. Лозунг партии формулируется как «Социальные преобразования и экономическое освобождение».

Самые крупные и влиятельные партии, а именно правящая Бхаратия Джаната Парти (БДП) и оппозиционная ИНК, с точки зрения лидеров БСП, являются сторонниками системы «манувади» ${ }^{1}$, т. е. защищают Ману. только высокорожденных хинду. Как последователи Амбедкара, который является знаменем и иконой их движения, лидеры БСП поддерживают идеи эгалитаризма и социальной справедливости.

В 2002 г. Канши Рам заявил о намерении принять буддизм в 50-ю годовщину обращения Амбедкара, т. е. 14 октября 2006 г. План Канши Рама подразумевал, что вместе с ним буддистами станут 20 млн его сторонников. Он не дожил до решающей даты, а его преемница Маявати Прабху Дас, известный политик, премьер-министр штата Уттар-Прадеш, изменила план обращения в буддизм, посчитав, что успешным оно будет в случае массовости, а это произойдет только с получением власти в центре: «Маявати заявляет, что она примет буддизм, когда реализуется мечта Амбедкара и Канши Рама о получении абсолютной власти в центре и некоторых штатах и когда она станет премьер-министром Индии: „В Индии после достижения независимости индуизм процветает, потому что премьер-министры и лидеры правящей партии - хинду. Из-за этого буддизмом пренебрегают. Если мы примем буддизм, не обладая властью, то только мы двое (Канши Рам и она сама. Д. А.) и будем обращены. Когда вы обладаете властью, вы можете начать настоящие изменения". Тем не менее, она подчеркнула, что Канши Рам и она следуют буддийским традициям и обычаям» [Mayawati 2006].

Хотя Бахуджан Самадж Парти является третьей в Индии по численности сторонников (уступая двум главным партиям очень существенно), ей не удалось получить на выборах в Лок Сабха в 2014 г. ни одного места, поскольку она не набрала необходимых $5 \%$ голосов.

Индуизм - идеологическое основание правящей Бхаратия Джаната Парти - остается главным лозунгом индийского национализма, причем политическую поддержку ему оказывают и те слои населения, на которые нацелены усилия амбедкарианских лидеров, т. е. индуизм как главная национальная религия не утрачивает своих позиций и в приоритетах общественного сознания, и в политике.

Тем не менее основатель Наваяны Амбедкар положил начало новой буддизации Индии, причем наибольшее число новообращенных приходится на период, когда самого Амбедкара уже не стало. С точки зрения теоретического осмысления обращения 
Амбедкара, состоявшегося в знаковый год 2500-летнего юбилея буддизма, несомненно, что оно было продиктовано главным образом протестом против дискриминации неприкасаемых в индусской Индии.

Если признать, что начатое Амбедкаром движение по возвращению буддизма в страну его возникновения является политическим действием, то столь же несомненным будет признание Наваяны в качестве буддийского модернизма. Его отличительной особенностью является идеологическая цель - отказ от индуизма. Иными словами, амбедкарианский буддизм - это в первую очередь «не индуизм»: «в действительности, в мире нет другой такой страны, в которой религия играла бы столь большую роль в истории, как в истории Индии. История Индии - это не что иное, как история смертельной войны между буддизмом и брахманизмом» [Ambedkar vol. 3, 2014: 267].

Десятилетия длившиеся противостояния между Амбедкаром и Ганди, между Наваяной и санатани-индуизмом завершились, учитывая последующие события, победой Ганди как создателя Индийской Нации, в которую входят все социальные группы, без учета существенных между ними конфликтов, религиозных и классовых. Правоту Ганди доказывают и результаты выборов после того, как ИНК перестал быть единственной реальной политической силой в стране. Прочные позиции на политической арене Индии в колониальный и постколониальный периоды занимают правые индусские партии, в частности, Бхаратия Джаната Парти ${ }^{1}$, созданная в 1980 г. как альянс сил, идеологически основывающихся, в отличие от светского ИНК, на индусском культурном национализме хиндутве. В периоды правления БДП значение прочих правых индусских организаций, таких как брахманская Хинду Махасабха и Раштрийя Сваямсевак Сангх, возрастает.

${ }^{1}$ Бхаратия Джаната Парти является преемницей партии Джаната (1977-1980), которая, в свою очередь, была преемницей партии Бхаратия Джана Сангх (1951-1977) - политического крыла крайне правой индусской организации Раштрия Сваямсевак Сангх. Активизация и победа коммуналистской партии оказались следствием социально-политического кризиса в Индии в 1970-е гг., когда конгрессистское правительство Индиры Ганди в результате серьезных ошибок настроило против себя большинство жителей Индии.
Амбедкарианские организации, в первую очередь, Республиканская партия Индии (выросшая из основанной Амбедкаром Федерации зарегистрированных каст) и партия Бахуджан Самадж, имеют значительное влияние в ряде штатов, но пока не способны изменить расстановку политических сил во всей стране. Однако при этом важно, что интересы далитов в индийской политике представлены самостоятельными партиями, а буддизм Наваяны, понимаемый как выбор в пользу демократии и социального равенства, приобретает в Индии все больше адептов.

\section{ИСТОЧНИКИ И ЛИТЕРАТУРА / SOURCES AND REFERENCES}

Ambedkar 1980 - Ambedkar B. R. Buddha and the Future of His Religion. Jullundur: Bheem Patrika Publications, 1980. 18 p. (In Eng.)

Ambedkar 1974 - Ambedkar B. R. The Buddha and His Dhamma. Bombay: Siddharth, 1974. 430 p. (In Eng.)

Dr. Ambedkar + Sangharakshita - Dr. Ambedkar + Sangharakshita. Bringing Buddhism Back to India [электронный pecypc] // The Buddhist Centre. URL: https://thebuddhistcentre. com/stories/ambedkar/ (дата обращения: 18.01.2018). [As aforesaid. An Internet resource: see hyperlink above (accessed: 18 January 2018). (In Eng.)]

Ambedkar 2014 - Dr. Babasaheb Ambedkar. Writings and speeches [электронный pecypc] // New Delhi: Dr. Ambedkar Foundation. 2014. In 18 volumes. URL: https://www. mea.gov.in/books-writings-of-ambedkar.htm (дата обращения: 12.01 - 22.04.2018). [As aforesaid. An Internet resource: see hyperlink above (accessed: 12 January - 22 April 2018). (In Eng.)]

Keer 1971 - Keer D. Dr. Ambedkar: Life and Mission. Mumbai: Popular Prakashan, 1971. 528 p. (In Eng.)

Mayawati 2006 - Mayawati claims Kanshi Ram's legacy [электронный ресурс] // Rediff India Abroad. 16.10.2006. URL: http://www.rediff. com/news/2006/oct/16look.htm?zcc=rl (дата обращения: 06.05.2018). [As aforesaid. An Internet resource: see hyperlink above (accessed: 6 May 2018). (In Eng.)]

Naik 2003 - Naik C. D. Thoughts and Philosophy of Dr. B. R. Ambedkar. N. Delhi: Sapur\&Sons, 2003. 475 p. (In Eng.)

Sangharakshita 2006 - Sangharakshita. Ambedkar and Buddhism. Delhi: Motilal Banarsidass Publishers, 2006. 187 p. (In Eng.) 
Sadangi 2008 - Sadangi H. C. Emancipation of Dalits and Freedom Struggle. Delhi: Isha Books, 2008. 416 p. (In Eng.)

Teltumbde 2017 - Teltumbde A. Dalits: Past,
Present and Future. NY: Routledge, 2017. 190 p. (In Eng.)

Wankhede 2009 - Wankhede D. M. Geographical

Thought of Dr. B. R. Ambedkar. Delhi: Gautam Book Centre edition, 2009. 281 p. (In Eng.)

UDC $294.311+94(540)$

\title{
Buddhism and Politicization of Religion in India: Bhimrao Ambedkar's Navayana
}

\author{
Darima D. Amogolonova ${ }^{1}$ \\ ${ }^{1}$ Ph.D. in History (Doct. of Historical Sc.), Leading Research Associate, Department of Philosophy, \\ Cultural and Religious Studies, Institute for Mongolian, Buddhist and Tibetan Studies of the Siberian \\ Branch of the RAS (6, Sakhjanova St., Ulan-Ude, 670031, Russian Federation). ORCID: 0000-0002- \\ 1176-4095. E-mail: amog@inbox.ru
}

\begin{abstract}
The paper deals with the political, social and religious activities by Bhimrao Ramji Ambedkar, the founder of the Navayana movement that is a modernized Buddhism in India. Being an outstanding politician and lawyer, Ambedkar devoted his life to the struggle for the rights of the untouchables to which he himself belonged. Ambedkar was convinced that the Hindu traditions namely varna-caste system were the main problems of India that prevented the formation of a united nation and civil society based on equality and freedom. To overcome traditional social organization and win over Hinduism, he turned to Buddhism which contained qualities to unite the nation and resist the Hindu rigid social stratification and hierarchy. According to Ambedkar, Navayana is most close to the traditional Teaching and, at the same time, is not monastic. In Navayana, Ambedkar sought the worldview alternative to Hinduism and ways to egalitarianism and democratization in the Indian society. In the course of struggle for independence, when Indian nationalism was built on the ideas of M.K. Gandhi who was closely associated with politicized Hinduism, Ambedkar did not put forward a national program of action and remained the leader of the untouchables that constituted a significant social group and were one of the objects of M.K. Gandhi's and the Indian National Congress's agitation. Gandhi. As a result, Ambedkar stood in opposition to the Hindu leaders, however gained political weight among various strata of Indian society. After achieving independence, Ambedkar actively joined the work for the creation of Indian legislative framework and became the 'Father of the Indian Constitution.' At the same time, he hoped to reform Hindu traditional law towards egalitarianism and democracy so as to improve the status of women and India's underclass which reportedly included the untouchables and minor tribes. However, when the attempts failed, Ambedkar became more decisive in his anti-Hindu agitation among the outcastes. The main event in Ambedkar's life was his own and his supporters' conversion to Buddhism in 1956. Modernized Buddhism - Navayana — is based on the principles that were formulated by Ambedkar according to the original Teachings of the Buddha as had been preserved in the Pali Canon. The number of Ambedkarian Buddhists grows as a result of the refusal of untouchables from Hinduism when India's supreme authorities stand on the positions of right Hindu nationalism and have no intention to change life of the most depressed social groups. The Navayana Buddhism and Ambedkar became the slogan and symbol of political parties and organizations, although today their weight in Indian politics is not that impressive. However, the growing number of supporters witnesses the fact that the ideas of egalitarianism and democracy once put forward by Ambedkar are getting increasingly widespread in India.
\end{abstract}

Keywords: Bhimrao Ambedkar, Navayana Buddhism, Hinduism, untouchables, varnas, castes 